\title{
ANÁLISE DA ASSOCIAÇÃO ENTRE CONSUMO ALIMENTAR E ADESÃO A UM PROGRAMA DE COMPOSTAGEM DOMÉSTICA
}

\author{
Mariana de C. Chaves*, Luana R. do V. e Garcia, Ana P. Bortoleto, Larissa M. Hara, Ligiana P. Corona
}

\section{Resumo}

Trata-se de um estudo de intervenção (ensaio) com 10 famílias do município de Campinas (SP) divididas igualitariamente em divididas em 2 grupos: controle e intervenção. O consumo alimentar foi avaliado através de: Questionário de Frequência Alimentar (QFA), Diário Alimentar de 3 dias não consecutivos, sendo 1 dia do fim de semana e Lista de Compras. Os itens do QFA foram classificados segundo o Guia Alimentar para População Brasileira: in natura, minimamente processados, processados, ultraprocessados, e óleos, gorduras, sal e açúcar (OGSA). A frequência de consumo dos itens foi padronizada em quantidade semanal e as diferenças entre antes e depois dos grupos foram analisadas pelo software Stata® versão 12, utilizando teste t-student pareado, com significância de $5 \%$. Não foi possível realizar análise estatística dos dados do Diário Alimentar e da Lista de Compras pois não houve adesão de todas as famílias às ferramentas.

\section{Palavras-chave:}

Transição nutricional, comportamento alimentar, compostagem doméstica.

\section{Introdução}

O perfil nutricional dietético brasileiro sofreu diversas alterações nas últimas décadas. Aumento do consumo de alimentos processados e ultraprocessados em detrimento dos alimentos in natura e minimamente processados (SOUZA et al., 2013), e aumento das prevalências de sobrepeso e obesidade (BATISTA FILHO \& RISSIN, 2003). Acompanhando os processos de urbanização e desenvolvimento tecnológico, a geração de resíduos sólidos no país aumentou ao longo dos anos $(0,96 \mathrm{~kg} /$ habitante $)$ e $41,6 \%$ são descartados inadequadamente (ABRELPE, 2014).

A compostagem doméstica surge como alternativa de descarte sustentável para os resíduos orgânicos produzidos no domicílio. O objetivo foi avaliar se houve mudanças no consumo alimentar após a adesão ao programa de compostagem.

\section{Resultados e Discussão}

Algumas famílias apresentaram variações na frequência de consumo de alguns itens do QFA, como aumento do consumo de queijos brancos, amarelos, e maionese e molhos de salada prontos em ambos os grupos. Entretanto, não observou-se diferença estatística pré e pós intervenção nos grupos conjuntos ou separados.

Tabela 1. Análise estatística dos grupos controle e intervenção conjuntos antes e após a intervenção.

\begin{tabular}{lccc}
\multicolumn{1}{c}{ Alimentos } & Pré & Pós & $\mathrm{p}$ \\
\hline In natura & 5,64 & 4,51 & 0,77 \\
Minimamente & 5,85 & 4,56 & 0,74 \\
processados & 2,11 & 1,83 & 0,34 \\
Processados & 3,65 & 3,23 & 0,38 \\
Ultraprocessados & 5,56 & 1,98 & 0,40 \\
OGSA &
\end{tabular}

Diversas possibilidades podem justificar a baixa significância estatística, o restrito tamanho da amostra, as ferramentas de avaliação, o curto período de acompanhamento do estudo e a não intervenção ou orientação nutricional.
Tabela 2. Análise estatística dos grupos controle e intervenção separados antes e após a intervenção

\begin{tabular}{lcccccc}
\hline \multirow{2}{*}{ Alimentos } & \multicolumn{3}{c}{ Controle } & \multicolumn{3}{c}{ Intervenção } \\
\cline { 2 - 7 } & Pré & Pós & $\mathrm{p}$ & Pré & Pós & $\mathrm{p}$ \\
\hline In natura & 9,58 & 8,04 & 0,11 & 3,80 & 4,34 & 0,32 \\
Minimamente & 11,96 & 7,61 & 0,84 & 2,98 & 5,82 & 0,79 \\
processados & 2,19 & 1,71 & 0,22 & 3,75 & 1,88 & 0,12 \\
Processados & 3,60 & 3,97 & 0,91 & 6,03 & 5,11 & 0,28 \\
Ultra & 10,75 & 2,68 & 0,48 & 4,14 & 3,21 & 0,76 \\
processados & OGSA &
\end{tabular}

Há evidências científicas demonstrando que manter 0 ambiente "neutro" sem alterações, como posposto no projeto, resulta em escolhas alimentares semelhantes às de ambientes "não saudáveis" (MOLLEN et al., 2013). A partir da orientação nutricional é possível estimular mudanças alimentares para um bom estado de saúde (FERREIRA, 2007).

\section{Conclusões}

Há pouca produção científica investigando a relação de comportamentos pró-ambientais e comportamento alimentar. Entretanto, já existem alguns avanços no entendimento da interferência de outros aspectos além dos tradicionais associados à saúde, como ambiente social. Atividades de educação nutricional ainda são os métodos mais utilizados para uma reeducação alimentar permanente. Mais estudos são necessários para avaliar o impacto de diferentes variáveis no padrão alimentar.

\section{Agradecimentos}

Agradeço ao PIBIC/CNPq pela disponibilização da bolsa, permitindo a realização do projeto.

SOUZA, A. de M.; PEREIRA, R.A.; YOKOO, E.B.; SICHIERI, R. Alimentos mais consumidos no Brasil: Inquérito Nacional de Alimentação 2008-2009. Rev. Saúde Pública, São Paulo, v. 47, n. 1, p. 190-199, 2013.

BATISTA FILHO, M.; RISSIN, A. A transição nutricional no Brasil: tendências regionais e temporais. Cad. Saúde Pública, Rio de Janeiro, v. 19, n. 1, p. 181-191, 2003.

ASSOCIAÇÃO BRASILEIRA DAS EMPRESAS DE LIMPEZA PÚBLICA ABRELPE. Panorama dos Resíduos Sólidos no Brasil 2014. 2014.

FERREIRA, V.A.; MAGALHÃES, R. Nutrição e Promoção da Saúde: Perspectivas Atuais. Cad. Saúde Pública, v. 23, n. 7, p. 1674-1681, 2007. MOLLEN, S., et al. Healthy and unhealthy social norms and food selection. Findings from a fiel-experiment. Appetite,v. 65, p. 83-89, 2013. 